\title{
IMPROVEMENT OF THE CRITERIA OF HYGIENIC ASSESSMENT OF NOISE IN THE ROOM OF HOUSING AND PUBLIC BUILDINGS
}

\author{
Semashko P.V., Kononova O.V. \\ УДОСКОНАЛЕННЯ КРИТЕРІЇв ГІГІЕНІЧНОї ОЦІНКИ ШУМУ \\ У ПРИМПЩЕННЯХ ЖИТЛОВИХ ТА ГРОМАДСЬКИХ БУДІВЕЛЬ
}

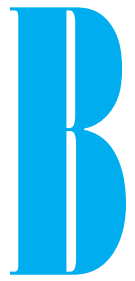

СЕМАШКО П.В., КОНОНОВА О.В. ДУ "Інститут громадського здоров'я ім. О.М. Марзєєва HAMHY", м. Київ

УДК 613.164:613.5

Ключові слова: криві NC,

допустимі рівні

звуку, допустимі рівні звукових тисків,

приміщення житлових

і громадських будівель, необхідна ізвукоізоляція. основу діючих в Україні СН № 3077-84 «Санитарные нормы допустимого шума в помещениях жилых и общественных зданий и на территории жилой застройки» покладено шумові критерії (NC), які розроблені Американською асоціацією інженерів систем опалення, вентиляції та кондиціювання наприкінці 1950-х років у відповідь на зростаючі проблеми в офісах, пов'язані з роботою систем опалення, вентиляції та кондиціювання повітря.

Криві NC були вперше опубліковані 1957 року, переглянуті у 1960 році [1, 2]. 3 того часу ведеться удосконалення цих кривих, яке стосується сприйняття людиною низькочастотних та високочастотних їхніх складових та підбору балансу між ними.

Дані критерії представлено 1971 року Американською Асоціацією Акустиків (ASA) у вигляді дійсних на той час сімейства кривих NC. Пізніше ці криві були удосконалені у стандарті ANSI S12.2-1995 American National standart. Criteria for Evalutiong Room Noise (критерії оцінки шуму у приміщеннях), який передбачав використання RC (розроблені у середині 1980-х років у відповідь на недоліки методу NC), RNC (для низькочастотних шумів), NCB (збалансовані) та RC
Mark II (розроблені у середині 1990-х у відповідь на недоліки співвідношення NC/RC) кривих [3].

Нові критерії NC розроблені у 2000-х роках у відповідь на недоліки співвідношення $\mathrm{NC} / \mathrm{RC}$

у 2008 році Американським національним інститутом стандартів було представлено новий стандарт ANSI S12.2-2008: Criteria for Evaluating Room Noise [4]. Оновлення цього стандарту стосувалося розширення допустимих рівнів звукових тисків октавними смугами 31,5 та 16 Гц для сімейства кривих NC та врахуванням розробок за іншими оновленими критеріями оцінки шуму у приміщеннях.

Таким чином, за час існування $\mathrm{CH}$ № 3077-84, 3'явилися нові дослідження, у результаті яких у країнах Європи та Америки змінилися допустимі рівні звуку та звукових тисків для приміщень житлових і громадських споруд. З урахуванням сказаного вище виникає питання про доцільність застосування рекомендованих ANSI S12.2-2008 допустимих рівнів звуку та звукових тисків для подібних приміщень в Україні.

Мета дослідження. Надати наукове обґрунтування для перегляду діючих в Україні СН № 3077-84
СОВЕРШЕНСТВОВАНИЕ КРИТЕРИЕВ

ГИГИЕНИЧЕСКОЙ ОЦЕНКИ ШУМА

В ПОМЕЩЕНИЯХ ЖИЛЫХ И ОБЩЕСТВЕННЫХ

ЗДАНИЙ

Семашко П.В., Кононова О.В.

ГУ «Институт общественного здоровья им. А.Н. Марзеева НАМН Украины», г. Киев

Цель исследования. Дать научное обоснование для пересмотра действующих в Украине санитарных норм СН № 34077-84 «Санитарные нормы допустимого шума в помещениях жилых и общественных зданий и на территории жилой застройки» и ДБН В.1.1-31:2013. „Защита территорий, домов и сооружений от шума".

Материалы и методы исследования. Анализ литературы по критериям оценки шума в помещениях жилых и общественных зданий. Расчет корректированных по шкале «А» уровней звука - по ДСТУ-Н Б В.1.1-35: 2013 «Руководство по расчету уровней шума в помещениях и на территориях» Приложение В. Расчет SIL - по ANSI S12.2-2008: Criteria for Evaluating Room Noise. Расчет необходимого снижения и требуемой звукоизоляции - по ДБН В.1.1-31:2013. Защита территорий, домов и сооружений от шума.

Результаты исследования. Доказано несоответ- ствие в СН № 3077-84 и ДБН В. 1. 1-31:2013 допустимых уровней звуковых давлений своим допустимым уровням звука, что приводит к неверной гигиенической оценке шума в помещениях и на территориях. Доказано, что применение допустимых уровней звуковых давлений СН № 3077-84 и ДБН В.1.1-31:2013 при расчете требуемой звукоизоляции ограждающих конструкций зданий приводит к занижению ее значений, что, в свою очередь, приводит к нарушению акустического режима помещений жилых и общественных зданий еще на стадиях их проектирования.

Рекомендованы допустимые уровни звука и звуковых давлений для помещений жилых и общественных зданий.

Выводы. Дано научное обоснование для пересмотра действующих в Украине санитарных норм СН № 34077-84 «Санитарные нормы допустимого шума в помещениях жилых и общественных зданий и на территории жилой застройки» и ДБН В. 1. 1-31:2013. „Защита территорий, домов и сооружений от шума". Ключевые слова: кривые NC, допустимые уровни звука, допустимые уровни звуковых давлений, помещения жилых и общественных зданий, требуемая звукоизоляция.

() Семашко П.В., Кононова О.В. СТАТТЯ, 2016. 
IMPROVEMENT OF THE CRITERIA OF HYGIE NIC ASSESSMENT OF NOISE IN THE ROOM OF HOUSING AND PUBLIC BUILDINGS

Semashko P.V., Kononova O.V.

State Institution "O.M. Marzeiev Institute for Public Health of the National Academy of Medical Sciences of Ukraine"

The scientific substantiations for the revision of existing Ukrainian sanitary norms SN № 34077-84 "Sanitary norms of allowable noise in residential and public buildings and in residential areas" and DBN V.1.1-31: 2013 «Protecting areas of houses and buildings from the noise.

Materials and methods. An analysis of the literature on the evaluation criteria of noise in residential and public buildings. Calculation of the corrected scale "A" sound levels - DSTU-NB V.1.1-35: 2013 "Guidelines for the calculation of noise levels in the rooms and in the territories" Appendix B.

Calculation of SIL - by ANSI S12.2-2008: "Criteria for Evaluating Room Noise". Calculation of the required reduction and the required insulation by DBN V.1.1-31: 2013. "Protecting areas of houses and buildings from the noise".
Results. The inconsistency in CH № 3077-84 and DBN V.1.1-31: 2013 according of permissible sound pressure level to its permissible sound levels was proved, which leads to incorrect hygienic assessment of noise in the rooms and in the territories. It was proved that the use of permissible sound pressure levels CH № 3077-84 and DBN V.1.1-31: 2013 , the calculation of the required sound insulation of building envelopes leads to an underestimation of its values, which in turn leads to disruption of the acoustic mode planned residential premises and public buildings is still at the design stage.

Recommended permissible sound levels and sound pressure for residential and public buildings.

Conclusions. The scientific basis for the revision of existing Ukrainian sanitary norms SN № 34077 84 "Sanitary norms of allowable noise in residential and public buildings and in residential areas" and DBN V.1.1-31: 2013 "Protecting areas of houses and buildings from the noise".

Keywords: NC curves, permissible sound levels, permissible sound pressure level, residential and public buildings, required sound insulation.
«Санитарные нормы допустимого шума в помещениях жилых и общественных зданий и на территории жилой застройки» та внесенню змін до ДБН В.1.131:2013. «Захист територій, будинків і споруд від шуму».

Для досягнення поставленої мети необхідно було провести порівняльний аналіз допустимих рівнів звуку та звукових тисків у приміщеннях житлових та громадських будівель нормативних документів України $(\mathrm{CH}$ № 3077-84, ДБН В.1.1-31:2013) 3 рекомендованими (в якості допустимих) рівнями стандарту ANSI S12.2-2008.

Методи дослідження. Розрахунок коректованих за шкалою «А» рівнів звуку виконували згідно 3 ДСТУ-Н Б В.1.1-35: 2013 «Настанова 3 розрахунків рівнів шуму у приміщеннях та на територіях». Додаток В. Розрахунок рівня мовних перешкод (SIL) проводили згідно з ANSI S12.2-2008: Criteria for Evaluating Room Noise. Розрахунок необхідного зниження та необхідної звукоізоляції виконували відповідно до ДБН В.1.1-31:2013. «Захист територій, будинків і споруд від шуму».

Допустимі рівні звуку та звукових тисків згідно з СН № 307784 та ANSI S12.2-2008 і їх аналіз представлено у таблицях 1 i 2.

За результатами порівняльного аналізу допустимих рівнів звуку та звукових тисків $\mathrm{CH}$ № 3077-84 та ANSI S12.2-2008, які наведено у таблицях 1 та 2, встановлено: діапазон допустимих рівнів звукових тисків ANSI S12.2-2008 розширено порівняно $3 \mathrm{CH}$ № 3077-84 на дві октавні смуги (до октавних смуг

\section{Допустимі рівні звуку та звукових тисків} згідно з СН № 3077-84 та їх аналіз

Таблиця 1

\begin{tabular}{|c|c|c|c|c|c|c|c|c|c|c|c|c|c|}
\hline \multirow{2}{*}{$\mathrm{NC}$} & \multicolumn{10}{|c|}{$\begin{array}{c}\text { Допустимі рівні звукового тиску, дБ, в октавних } \\
\text { смугах з середньогеометричними значеннями } \\
\text { частот, Гц }\end{array}$} & \multirow{2}{*}{ 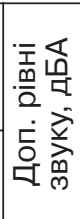 } & \multirow{2}{*}{ 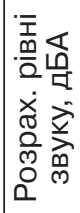 } & \multirow{2}{*}{ 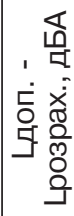 } \\
\hline & 16 & 32 & 63 & 125 & 250 & 500 & 1000 & 2000 & 4000 & 8000 & & & \\
\hline NC-20 & - & - & 51 & 39 & 31 & 24 & 20 & 17 & 14 & 13 & 25 & 30,0 & 5,0 \\
\hline NC-25 & _ & _- & 55 & 44 & 35 & 29 & 25 & 22 & 20 & 18 & 30 & 34,6 & 4,6 \\
\hline NC-30 & _ & - & 59 & 48 & 40 & 34 & 30 & 27 & 25 & 23 & 35 & 39,2 & 4,2 \\
\hline NC-35 & - & _- & 63 & 52 & 45 & 39 & 35 & 32 & 30 & 28 & 40 & 43,8 & 3,8 \\
\hline NC-40 & - & - & 67 & 57 & 49 & 44 & 40 & 37 & 35 & 33 & 45 & 48,4 & 3,4 \\
\hline NC-45 & - & - & 71 & 61 & 54 & 49 & 45 & 42 & 40 & 38 & 50 & 53,1 & 3,1 \\
\hline NC-50 & - & - & 75 & 66 & 59 & 54 & 50 & 47 & 45 & 43 & 55 & 58,0 & 3,0 \\
\hline NC-55 & - & - & 79 & 70 & 63 & 58 & 55 & 52 & 50 & 49 & 60 & 62,4 & 2,4 \\
\hline NC-60 & - & - & 83 & 74 & 68 & 63 & 60 & 57 & 55 & 54 & 65 & 67,1 & 2,1 \\
\hline & & & & & & & & & & & & & 3, \\
\hline
\end{tabular}

Допустимі рівні звуку та звукових тисків

Таблиця 2 згідно з ANSI S12.2-2008 та їх аналіз

\begin{tabular}{|c|c|c|c|c|c|c|c|c|c|c|c|c|c|}
\hline \multirow{2}{*}{$\lambda$} & \multicolumn{10}{|c|}{$\begin{array}{c}\text { Допустимі рівні звукового тиску, дБ, в октавних } \\
\text { смугах з середньогеометричними значеннями } \\
\text { частот, Гц }\end{array}$} & \multirow{2}{*}{ 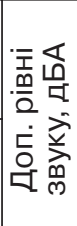 } & \multirow{2}{*}{ 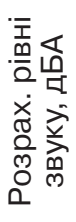 } & \multirow{2}{*}{ 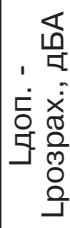 } \\
\hline & 16 & 32 & 63 & 125 & 250 & 500 & 1000 & 2000 & 4000 & 8000 & & & \\
\hline C-20 & 79 & 63 & 50 & 40 & 33 & 26 & 2 & 20 & 1 & 16 & 30 & 32,4 & 2,4 \\
\hline NC-25 & 80 & 65 & 54 & 44 & 37 & 31 & 27 & 24 & 22 & 22 & 35 & 36,3 & 1,3 \\
\hline NC-30 & 81 & 68 & 57 & 48 & 41 & 35 & 32 & 29 & 28 & 27 & 40 & 40,3 & 0,3 \\
\hline NC-35 & 82 & 71 & 60 & 52 & 45 & 40 & 36 & 34 & 33 & 32 & 45 & 44,5 & $\overline{0,5}$ \\
\hline-40 & 84 & 74 & 4 & 56 & 50 & 44 & 41 & 39 & 38 & 37 & 50 & 49,0 & -1 \\
\hline NC-45 & 85 & 76 & 67 & 60 & 54 & 49 & 46 & 44 & 43 & 42 & 55 & 53,5 & $-1,5$ \\
\hline NC-50 & 87 & 79 & 71 & 64 & 58 & 54 & 51 & 49 & 48 & 47 & 60 & 58,2 & $-1,8$ \\
\hline NC-55 & 89 & 82 & 74 & 67 & 62 & 5 & 56 & 54 & 5 & 52 & 65 & 62,6 & $-2,4$ \\
\hline NC-60 & 90 & 85 & 77 & 71 & 66 & 63 & 60 & 59 & 58 & 57 & 70 & 67,2 & $-2,8$ \\
\hline \multicolumn{13}{|c|}{ ерепня } & 0 , \\
\hline
\end{tabular}


31,5 та 16 Гц); в ANSI S12.22008 більш жорсткі вимоги до допустимих рівнів звукових тисків (наприклад, якщо у $\mathrm{CH}$ № 3077-84 допустимому рівню звуку 30 дБА відповідає крива NC 25, то в ANSI S12.2-2008 крива NC 20). Треба зауважити, що більш жорсткі вимоги до допустимих рівнів призводять до збільшення необхідного зниження рівнів звуку та звукових тисків огороджувальною конструкцією $\left(\Delta \mathrm{L}^{\mathrm{Hx}}\right)$, що, у свою чергу, потребує підвищення її необхідної звукоізоляції $\left(\mathrm{R}^{\mathrm{\mu x}}\right)$ або зниження рівнів у джерелі; зміна допустимих спектрів звукових тисків потребувала перевірки відповідності цих спектрів своєму інтегральному показнику - корегованому за шкалою А допустимому рівню звуку. Встановлено, що допустимі спектри (які представлені рівнями звукових тисків) СН № 3077-84 погано відповідають розрахунковим рівням звуку у дБА (рис. 1). Допустимі рівні звукових тисків ANSI S12.2-

\section{Порівняння допустимих рівнів звуку СН № 3077-84} з розрахунковими

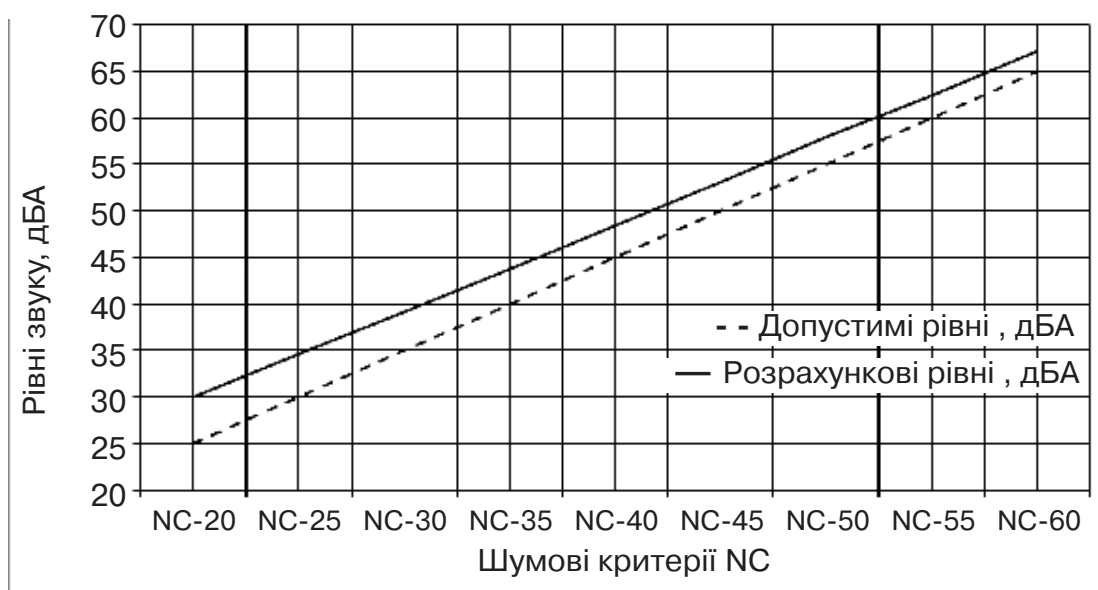

Порівняння допустимих рівнів звуку ANSI S12.2-2008 з розрахунковими

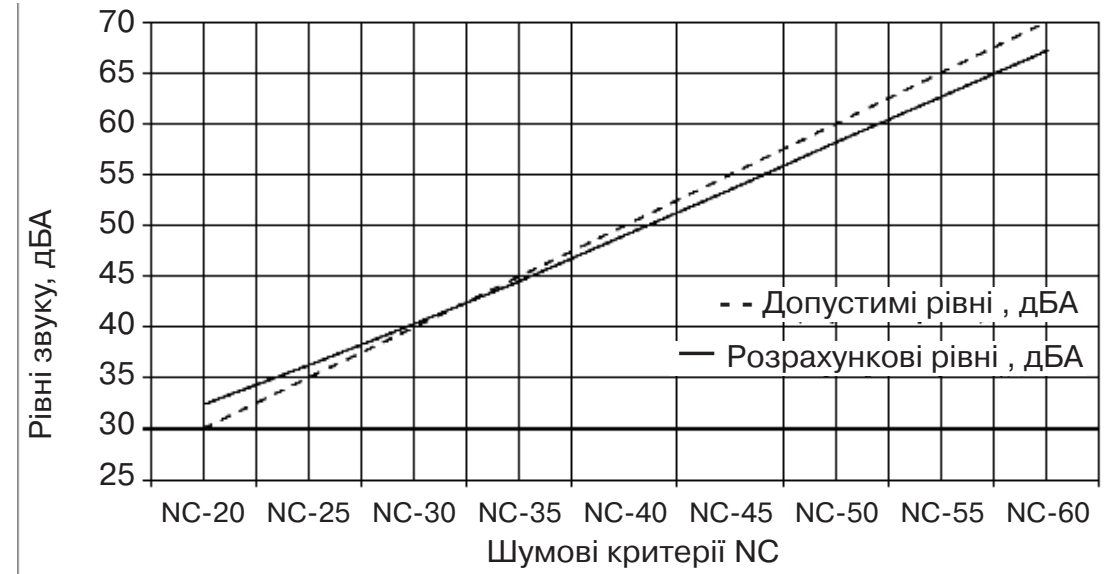

обов'язково треба застосовувати шумозахисні вікна, які забезпечують нормативний повітрообмін у приміщенні.

у нових санітарних нормах слід відмовитися від поправки -5 дБА до систем опалення, вентиляції та кондиціювання повітря, оскільки криві NC розроблені з урахуванням суб'єктивної оцінки впливу цих систем на людину, таким чином, додаткове врахування цього впливу не має сенсу.

Практична реалізація такої невідповідності у СН № 3077-84 «Санитарные нормы допустимого шума в помещениях жилых и общественных зданий и на территории жилой застройки" та ДБН В.1.1-31:2013 «Захист територій, будинків і споруд від шуму», з нашої точки зору, призводить до будівництва житлових та громадських будівель з заниженою звукоізоляцією огороджувальних конструкцій. Наприклад, проектувальнику огороджувальної конструкції необхідно забезпечити досягнення допустимого рівня у житловому приміщенні 30 дБА. Для розрахунку необхідної звукоізоляції він використовує спектр, наданий у СН № 3077 84, який відповідає допустимому рівню звуку 30 дБА. Після чого звітує, що дана звукоізоляція забезпечить у приміщенні допустимий рівень звуку 30 дБА. Фактичний же рівень звуку, який відповідає даному спектру (35 дБА), що вже на стадії проектування закладає факт порушення акустичного стану у житловому приміщенні на 5 дБА. Факт невідповідності спектрів допустимих рівнів звукових тисків СН № 3077-84 допустимим рівням звуку було встановлено нами ще 1994 року і наведено у роботі [5].

Нижче представлено результати розрахунків необхідної звукоізоляції огороджувальної конструкції при застосуванні вимог CH № 3077-84 та ANSI S12.22008.

3 представлених у таблиці 3 результатів видно, що застосування допустимих рівнів звукового тиску згідно з СН № 3077 84 призводить до заниження необхідної звукоізоляції огороджувальної конструкції від 2 до 5 дБ.

Таким чином, на підставі проведеного аналізу встановлено доцільність перегляду допустимих рівнів звуків та звукових тисків для приміщень, які представлені у СН № 3077-84. 
Рекомендовані допустимі рівні звукових тис- 등 ків та допустимі рівні звуку для конкретнихб приміщень представлено у таблицях С1 та С2 додатку C стандарту ANSI S12.2-2008 [4]. Узагальнені нами дані цих додатків представлено у таблиці 4

Як видно з даних таблиці 4, рекомендовані рівні представлені у вигляді діапазонів, що, на нашу думку, зумовлено конкретним призначенням приміщення та рівнем його комфортності. 3 наведених даних також видно, що у стандарті ANSI S12.2-2008 відсутні рекомендації для приміщень 3 перебуванням людини у них у нічний час доби та територій. Таким чином, обґрунтування допустимих рівнів для територій $€$ окремою задачею при написанні нових санітарних норм, тому що їх визначення залежить від багатьох факторів (фізичних, психофізіологічних, соціальних, економічних тощо) і конкретних ситуацій. На підставі сказаного вище ণ та 3 урахуванням таблиць C1 та C2 додатку C стандарту ANSI S12.22008 в якості допустимих для приміщень житлових і громадських будівель нами рекомендуються рівні звуків та звукових тисків, які представлено у таблиці 5.

Допустимі рівні у нічний час визначали шляхом застосування загальноприйнятої поправки на час доби -10 дБ(А) згідно з таблицею А. 1 стандарту ISO 1996-1:2003. При цьому згідно з таблицею A.1 стандарту ISO 19961:2003 також обов'язково слід враховувати у нових санітарних нормах вид транспортного потоку (якщо є вплив транспортного потоку).

Отримані результати. Встановлео невідповідність у СН № 3077-84 допустимих рівнів звукових тисків своїм допустимим рівням звуку.

Доведено, що застосування допустимих рівнів звукового тиску згідно з

\begin{tabular}{|c|c|c|c|c|c|c|c|c|}
\hline \multirow[t]{2}{*}{ Критерії до розрахунку } & \multicolumn{8}{|c|}{$\begin{array}{l}\text { Параметри критеріїв в октавних смугах } \\
\text { з середньогеометричною частотою, Гц }\end{array}$} \\
\hline & 63 & 125 & 250 & 500 & 1000 & 2000 & 4000 & 8000 \\
\hline $\begin{array}{l}\text { Октавний рівень звукового } \\
\text { тиску на території, дБ }\end{array}$ & 70,0 & 60,5 & 64,8 & 67,8 & 71,1 & 68,6 & 60,0 & 55,0 \\
\hline $\begin{array}{l}\text { Постійна приміщення, } \\
\text { яке ізолюється, } \text { м² }^{2}\end{array}$ & 8,6 & 13,6 & 14,9 & 16,2 & 17,6 & 20,5 & 22,3 & 26,9 \\
\hline Площа огородження, м² & 4,0 & 4,0 & 4,0 & 4,0 & 4,0 & 4,0 & 4,0 & 4,0 \\
\hline $\begin{array}{l}\text { Коефіцієнт, який враховує } \\
\text { порушення дифузності } \\
\text { звукового поля }\end{array}$ & 1,25 & 1,25 & 1,25 & 1,25 & 1,25 & 1,25 & 1,25 & 1,25 \\
\hline $\begin{array}{l}\text { Допустимі октавні рівні } \\
\text { звукового тиску, які } \\
\text { відповідають рівню звуку } \\
30 \text { дБА (СН № 3077-84) }\end{array}$ & 55,0 & 44,0 & 35,0 & 29,0 & 25,0 & 22,0 & 20,0 & 18,0 \\
\hline $\begin{array}{l}\text { Допустимі октавні рівні } \\
\text { звукового тиску, які відпо- } \\
\text { відають рівню звуку } 30 \text { дБА } \\
\text { (ANSI S12.2-2008: Criteria for } \\
\text { Evaluating Room Noise) }\end{array}$ & 50,0 & 40,0 & 33,0 & 26,0 & 22,0 & 20,0 & 17,0 & 16,0 \\
\hline $\begin{array}{l}\text { Необхідна звукоізоляція } \\
\text { при врахуванні вимог до } \\
\text { допустимих рівнів } \\
\text { звукового тиску згідно } \\
\text { з СН № 3077-84 }\end{array}$ & 10,7 & 10,3 & 23,2 & 31,8 & 38,7 & 38,5 & 31,6 & 27,8 \\
\hline $\begin{array}{l}\text { Необхідна звукоізоляція } \\
\text { при врахуванні вимог до } \\
\text { допустимих рівнів звуко- } \\
\text { вого тиску згідно з ANSI } \\
\text { S12.2-2008: Criteria for } \\
\text { Evaluating Room Noise }\end{array}$ & 15,7 & 14,3 & 25,2 & 34,8 & 41,7 & 40,5 & 34,6 & 29,8 \\
\hline $\begin{array}{l}\text { Rнеобх. ANSI S12.2-2008 - } \\
\text { Rнеобх. CH 3077-84 }\end{array}$ & 5,0 & 4,0 & 2,0 & 3,0 & 3,0 & 2,0 & 3,0 & 2,0 \\
\hline
\end{tabular}

\begin{tabular}{|c|c|c|}
\hline Приміщення & $\begin{array}{l}\text { Рекомендовані } \\
\text { рівні звуку, дБА } \\
\text { (від/до) }\end{array}$ & $\begin{array}{c}\text { Рекомендовані NC } \\
\text { критерії (діапазон: } \\
\text { від/до) }\end{array}$ \\
\hline \multicolumn{3}{|c|}{ Лікарні та клініки } \\
\hline палата на одного пацієнта & $35-39$ & $25-30$ \\
\hline палати & $39-44$ & $30-35$ \\
\hline операційні & $35-44$ & $25-35$ \\
\hline лабораторії & $44-53$ & $35-45$ \\
\hline публічні зони & $48-52$ & $40-45$ \\
\hline \multicolumn{3}{|c|}{ Житлові приміщення } \\
\hline спальні & $35-39$ & $25-30$ \\
\hline апартаменти & $39-48$ & $30-40$ \\
\hline гостьові & $39-48$ & $30-40$ \\
\hline \multicolumn{3}{|c|}{ Готелі/мотелі } \\
\hline номери & $39-44$ & $30-35$ \\
\hline кімнати для зустрічей/банкетні & $35-44$ & $25-35$ \\
\hline \multicolumn{3}{|c|}{ Школи } \\
\hline $\begin{array}{l}\text { лекційні та класні приміщення } \\
\text { об'ємом <566 м }\end{array}$ & 35 & $25-30$ \\
\hline $\begin{array}{l}\text { лекційні та класні приміщення } \\
\text { об'ємом >566 м³ }\end{array}$ & 40 & $30-35$ \\
\hline Класні кімнати відкритого плану & 35 & $25-35$ \\
\hline Аудиторії (<500 місць) & $35-39$ & $25-30$ \\
\hline Аудиторії ( $\geq 500$ місць) & $30-35$ & $20-25$ \\
\hline Бібліотеки & $44-48$ & $35-40$ \\
\hline Ресторани & $48-52$ & $40-45$ \\
\hline Магазини та гаражі & $57-67$ & $50-60$ \\
\hline Маленькі церкви & $39-44$ & $30-35$ \\
\hline Великі церкви ( $\geq 500$ місць) & $30-35$ & $20-25$ \\
\hline Зали судових засідань & $39-44$ & $30-35$ \\
\hline
\end{tabular}


CH № 3077-84 призводить до заниження необхідної звукоізоляції огороджувальних конструкцій.

Рекомендовано допустимі рівні звуку та звукових тисків для житлових та громадських приміщень.

Таблиця 5

Допустимі рівні звуку та звукових тисків

\begin{tabular}{|c|c|c|c|}
\hline Призначення приміщень та територій & $\begin{array}{c}\text { Час } \\
\text { доби }\end{array}$ & $\begin{array}{l}\text { LA або LA } \\
\text { екв., дБА }\end{array}$ & NC \\
\hline Операційні приміщення у лікарнях & доба & 35 & 25 \\
\hline \multicolumn{4}{|l|}{ Палати лікарень і санаторіїв: } \\
\hline \multirow{2}{*}{ палата на одного пацієнта } & день & 35 & 25 \\
\hline & Hí & 25 & 15 \\
\hline \multirow{2}{*}{ палати } & день & 40 & 30 \\
\hline & ніч & 30 & 20 \\
\hline $\begin{array}{l}\text { Кабінети лікарів, масажні та косметологічні } \\
\text { кабінети, аптеки }\end{array}$ & & 40 & 30 \\
\hline \multirow{2}{*}{$\begin{array}{l}\text { Житлові приміщення будинків відпочинку, } \\
\text { пансіонатів, інтернатів для літніх людей та інвалідів }\end{array}$} & день & 40 & 30 \\
\hline & $\mathrm{Hi4}$ & 30 & 20 \\
\hline \multirow{2}{*}{$\begin{array}{l}\text { Спальні приміщення у дитячих дошкільних закла- } \\
\text { дах і школах-інтернатах }\end{array}$} & день & 40 & 30 \\
\hline & Hí & 30 & 20 \\
\hline \multicolumn{4}{|l|}{ Житлові приміщення квартир: } \\
\hline \multirow{2}{*}{ спальні у приміщеннях підвищеної комфортності } & день & 35 & 25 \\
\hline & Hіч & 25 & 15 \\
\hline \multirow{2}{*}{ спальні в інших квартирах } & день & 40 & 30 \\
\hline & Hiч & 30 & 20 \\
\hline \multirow{2}{*}{$\begin{array}{l}\text { гостьові та апартаменти у квартирах підвищеної } \\
\text { комфортності }\end{array}$} & день & 40 & 30 \\
\hline & Hí & 30 & 20 \\
\hline \multirow{2}{*}{ гостьові та апартаменти в інших квартирах } & день & 50 & 40 \\
\hline & ніч & 40 & 30 \\
\hline \multirow{2}{*}{ Житлові кімнати у будівлях гуртожитків } & день & 45 & 35 \\
\hline & ніч & 35 & 25 \\
\hline \multicolumn{4}{|l|}{ Житлові номери готелів: } \\
\hline \multirow{2}{*}{ категорії 4 зірки і 5 зірок } & день & 35 & 25 \\
\hline & Hí & 30 & 20 \\
\hline \multirow{2}{*}{ категорії 3 зірки } & день & 40 & 30 \\
\hline & Hí & 30 & 20 \\
\hline \multirow{2}{*}{ категорії менше ніж 3 зірки } & день & 45 & 40 \\
\hline & ніч & 35 & 25 \\
\hline $\begin{array}{l}\text { Класи, кабінети, кімнати викладачів, аудиторії } \\
\text { шкіл та інших учбових закладів }\end{array}$ & & 40 & 30 \\
\hline Музичні класи & & 40 & 30 \\
\hline $\begin{array}{l}\text { Робочі приміщення офісів, банків, кабінети і } \\
\text { приміщення в адміністративних будівлях }\end{array}$ & & 50 & 40 \\
\hline $\begin{array}{l}\text { Робочі приміщення і кабінети наук.-дослідних і } \\
\text { проектно-конструкторьких організацій }\end{array}$ & & 50 & 40 \\
\hline Конференц-зали, читальні зали бібліотек & & 40 & 30 \\
\hline $\begin{array}{l}\text { Зали для глядачів у клубах, кінотеатрах, закладах } \\
\text { дозвілля, зали засідань і судових нарад }\end{array}$ & & 40 & 30 \\
\hline $\begin{array}{l}\text { Фойє кінотеатрів, клубів, багатоцільових залів, } \\
\text { закладів для дозвілля }\end{array}$ & & 55 & 45 \\
\hline Музеї та храми з кількістю місць менше 500 місць & & 40 & 30 \\
\hline Храми (понад 500 місць) & & 35 & 25 \\
\hline Спортивні зали, плавальні басейни & & 55 & 45 \\
\hline Зали кафе, їдалень, барів, ресторанів & & 55 & 45 \\
\hline $\begin{array}{l}\text { Торговельні зали магазинів, пасажирські зали } \\
\text { аеропортів і вокзалів, приймальні пункти } \\
\text { підприємств побутового обслуговування }\end{array}$ & & 60 & 50 \\
\hline
\end{tabular}

Встановлено необхідність перегляду допустимих рівнів звуків та звукових тисків для житлових та громадських приміщень.

Встановлено необхідність перегляду допустимих рівнів звуків та звукових тисків для сельбищних територій.

Встановлено недоцільність застосування поправки -5 дБА до систем опалення, вентиляції та кондиціювання повітря при розробці нових санітарних норм.

\section{Висновки}

Санітарні норми СН № 307784 «Санитарные нормы допустимого шума в помещениях жилых и общественных зданий и на территории жилой застройки» потребують перегляду.

В основу нових санітарних норм допустимих рівнів шуму у приміщеннях і на територіях рекомендується покласти стандарт ANSI S12.2-2008: Criteria for Evaluating Room Noise.

ЛІТЕРАТУРА

1. Beranek L.L. Revesed criteria for noise in buildings / L.L. Baranek // Noise Control. - 1957. - № 3. - P. 19-27.

2. Beranek L.L. Noise Reduction. - McGraw-Hill Book Co., 1960. - 519 p.

3. ANSI S12.2-1995 American National Standard. Criteria for Evaluating Room Noise.

4. ANSI S12.2-2008 Criteria for Evaluating Room Noise. ANSI Approved.

5. Семашко П.В. Гігієнічна оцінка та нормування шуму в октавних смугах з середньогеометричними значеннями частот 16 та 31,5 Гц : автореф. дис. : 03.00.16 / П.В. Семашко. Київ, 1994. - 25 с.

REFERENCES

1. Beranek L.L. Noise Control. $1957 ; 3: 19-27$.

2. Beranek L.L. Noise Reduction. McGraw-Hill Book Co. :1960 : 519 p

3. ANSI S12.2-1995 American National Standard. Criteria for Evaluating Room Noise.

4. ANSI S12.2-2008 Criteria for Evaluating Room Noise. ANSI Approved.

5. Semashko P.V. Hihiienichna otsinka ta normuvannia shumu v oktavnykh smuhakh z serednoheometrychnymy znachenniamy chastot 16 ta 31,5 Hts : avtoref. dys. [Hygienic Assessment and Standardization of the Noise in the Octave Noises with 16 and $31.5 \mathrm{~Hz}$ Frequencies' Geometric Average Meanings]. Kyiv ; 1994 : 25 p. (in Ukrainian).

Надійшла до редакції 19.10.2015 